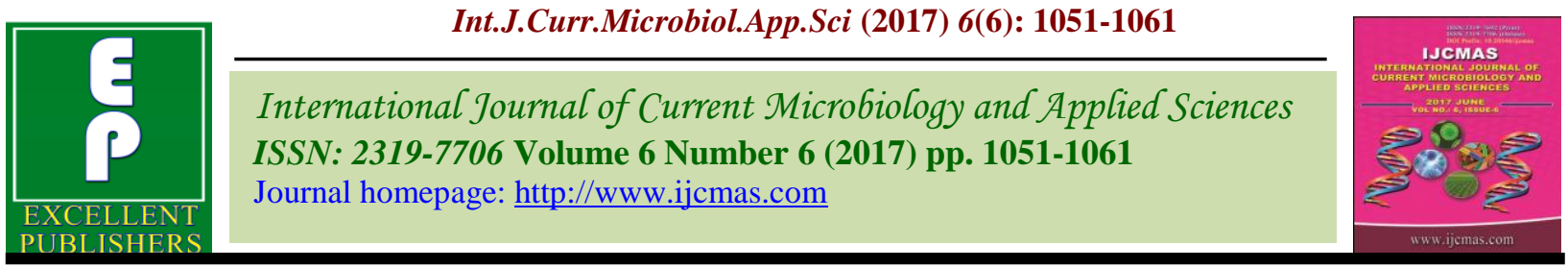

Original Research Article

https://doi.org/10.20546/ijcmas.2017.606.121

\title{
Effect of Operational Parameters of Selected Tillage Tools in Soil Bin
}

\author{
Shrinivas Deshpande* and Sunil Shirwal \\ University of Agricultural Sciences, Raichur, Karnataka, India \\ *Corresponding author
}

A B S T R A C T

The effect of operational parameters on selected tillage tools or tines were studied by using instrumented soilbin at Department of Farm Machinery and Power Engineering, College of Agricultural Engineering, Raichur (Karnataka). The experiment was conducted in sandy clay loam soil to study the effect of variation of forward speed $(3,4$ and $5 \mathrm{~km} / \mathrm{h})$, operating depth $(5,10$ and $15 \mathrm{~cm})$ and type of tools (Sweep-1, Sweep-2 and Shovel-1) on draft, specific draft, soil disturbance parameters and tool width to furrow width ratio. The test was conducted in a $21 \mathrm{~m}$ long, $2 \mathrm{~m}$ wide and $1 \mathrm{~m}$ deep soilbin. By altering the combination of speed and operating depth, the response of all parameters were studied for each tool. The results obtained after each run were tabulated and further analyzed through Design Experts 7.0.0 software for optimization of data. It was observed that, at $5 \mathrm{~km} / \mathrm{h}$ forward speed and $15 \mathrm{~cm}$ operating depth, the Sweep-2 gives the maximum value of draft $(1,208.33$ N). Similarly, at $5 \mathrm{~cm}$ operating depth and $3 \mathrm{~km} / \mathrm{h}$ forward speed, Shovel-1 gives the minimum value of draft $(193.67 \mathrm{~N})$. The maximum value of specific draft was observed for Sweep-1 $(15.17 \mathrm{~N} / \mathrm{sq} . \mathrm{cm})$ at depth-1 $(5 \mathrm{~cm})$ and speed-2 $(4 \mathrm{~km} / \mathrm{h})$. Similarly, the minimum value was observed for Shovel-1 $(1.51 \mathrm{~N} / \mathrm{sq} . \mathrm{cm})$ at depth-2 $(10 \mathrm{~cm})$ and speed-1 $(3 \mathrm{~km} / \mathrm{h})$. For Sweep-2, the specific draft values observed were greater than Shovel-1 and less than Sweep-1. The effect of depth of operation of the different sweeps and shovel on soil disturbance was observed for a forward speed of 3,4 and $5 \mathrm{~km} / \mathrm{h}$. The width of the tool strongly influenced the soil disturbance parameters as they all increased as the working depth increased but less proportionately. In this experiment, the minimum value of the tool to furrow width ratio was observed for Sweep-1 (1.36) at speed-2 and depth-3, whereas the maximum value was observed (3.56) at depth-1 and speed-1.

\section{Introduction}

Soil tillage aims to control weeds, organic matter incorporation into soil and improvement of soil structure. Optimizing the tillage tool geometry and working conditions also minimizes the number of subsequent tillage operations required. So, the total energy input for a given tillage system decreases. For reducing the tillage operations and energy requirement, it is important to know the draft requirements for different tillage tool geometry (Marakoglu and
Carman, 2009). Agricultural tools for a long time have been designed on trial and error basis as soil-tool interactions have not been well defined and quantified. Accurate knowledge of draft and energy requirement of tillage implements is essential for proper design of the implements, appropriate matching of the implements with their power sources and the selection of the optimum operation conditions (Ademosun, 1990). More research needs to be conducted to 
clearly understand the mechanics of soil under the influence of agricultural tillage tools (Makanga et al., 1997). The type and degree of soil disturbance is the prime factor when selecting tillage implements but this must be considered together with the draft and penetration force requirements for efficient operation (Goodwin, 2007). Wings or sweeps attached to the foot of the tine modify the type of soil disturbance as shown by the work of Spoor and Godwin (Spoor and Godwin, 1978) by doubling the disturbed area for an increase in draft force of $30 \%$. This significantly increases the effectiveness of the operation, by reducing the specific resistance (draft/disturbed area) by $30 \%$. The draft requirement of tillage tools as a function of operating speed is an important criterion for evaluating tillage implements either by field and/or laboratory testing. As early as 1908, Davidson and Chase (Davidson and Chase, 1908) described equipment to measure draft and operating speed. Since then many investigations have been carried out. The effect of speed on implement draft depends on the soil type and the type of implement. It has been widely reported that the draft forces on implements increase significantly with speed and the relationship varies from linear to quadratic (Grisso et al., 1994).

There have been intensive research efforts to obtain a better understanding of the soil- tool interaction due to the complex problems of interaction between the various devices (tillage tools, wheel, etc.) and various type conditions of soil surfaces (Mardani et al., 2010). Tractive performance of tractors has been a challenging problem for many engineers. The tests are conducted either on soilbin found in indoor testing facilities or by performing real field testing. Usually, the soil parameters in soil bins such as variation of cone index and soil compaction level are more constant. Generally, a soil bin facility consists of soil bin, tool carriage, drive system, instrumentation and data acquisition systems. Soilbins are grouped into two design classes. One class of soilbin consists of straight or circular rails, movable soil bin in which the tested tool remains stationary. Another class involves fixed soil bin with a carriage that travels over the soil. Most of the early studies on different soils were done in the field using full scale or commercial implements. It has also been reported Janobi and Eldin (Al-Janobi and Eldin, 1997) that, due to the wide variation of soil types and conditions in the field, the results obtained were sometimes meaningless. Also the chance of getting the same soil at the same condition for repeating the experiment was very rare. Such problems were largely overcome by the adequacy of soil bin facility in soil-tillagetool interaction studies, elimination of the experimental field difficulties, controlled studies are possible in soil bins where the operating parameters can be controlled and the experiments closely observed and monitored.

\section{Materials and Methods}

The experiments were conducted in Department of Farm Machinery and Power Engineering, College of Agricultural Engineering, Raichur (Karnataka). The soilbin has $21 \mathrm{~m}$ long, $2 \mathrm{~m}$ wide and $1 \mathrm{~m}$ deep and for present experiment locally available sandy clay loam soil was selected. To know the characteristics of selected soil, some of basic soil properties were measured like initial moisture content $(14 \% \mathrm{db})$, bulk density $\left(1.55 \mathrm{~g} / \mathrm{cm}^{3}\right)$, cone index $\left(3.6 \mathrm{~kg} / \mathrm{cm}^{2}\right)$ at $0-15 \mathrm{~cm}$ depth, liquid limit $(9.0 \%)$, plastic limit $(7.80 \%)$ and soil texture (sand $55 \%$, silt $22 \%$ and clay $23 \%$ ) were measured before starting of the experiment using standard method recommended (reference).

The soilbin equipment consists of an outdoor soil bin of $21 \mathrm{~m}$ length, $2 \mathrm{~m}$ width and $1 \mathrm{~m}$ 
depth; a soil processing trolley with a leveling blade, compaction roller, a tool carriage, a power transmission system with a $3.1 \mathrm{~kW}$ electric motor as prime mover, a tool mounting frame, a tool and cone penetrometer with LVDT is provided.

The study was conducted according to the plan to observe the effect of operational parameters on various dependent parameters.

The aim of the experiment was to evaluate the draft requirement, specific draft and soil disturbance parameters by three commonly used tillage tools under different operational conditions at different operating speed $(3,4$ and $5 \mathrm{~km} / \mathrm{h})$ and working depth $(5,10$ and 15 $\mathrm{cm})$ using soil bin as per the plan of work (Table 1).

The different observations were taken which includes draft, specific draft, soil disturbance parameters and tool width to furrow width ratio were recorded for each run test. All the test runs for replicated three times to overcome any experimental bias.

All the experiments were conducted in a same type of soil in the same soilbin. For every replication according to the plan of work, the test set up was operated for each tool but at three different levels of forward speed and working depth. The observation on draft, soil disturbance parameters and tool width to furrow width ratio for all three levels of speed and depth were replicated. The procedure is repeated for remaining two tools and observations were recorded. Further Data were analyzed to detect significant differences by ANOVA at a significance level of 0.01 and 0.05. The software used for ANOVA procedure was Design Expert 7.0.0 for windows. The standard deviation and coefficient of variation were also calculated for above experiment.

\section{Measurement of dependent parameters}

\section{Measurement of draft and specific draft}

Draft and specific draft is very important parameters for measuring and evaluating performance of tillage tools. The draft was directly measured with the help of EORT (Extended Octagonal Ring Transducer) by recording horizontal force. The data was recorded continuously at $50 \mathrm{~Hz}$ data logging software "CATMAN EASY" AND "SPIDER 8 " signals processor, the average draft value was recorded and obtained in MS-EXCEL format.

Calculation of specific draft: After tillage, all the dimensions of the furrow were recorded. From this dimensions cross sectional area of the furrow was calculated. When the working depth was known, specific draught $\left(\mathrm{N} / \mathrm{cm}^{2}\right)$ was calculated as the draught force divided by working depth and width of the implement.

\section{Soil disturbance parameters}

Soil disturbance is one of the important parameter to quantify the tillage work; it mainly depends upon, tool shape, tool geometry, depth of operation, speed of operation and soil condition. The general form of soil disturbance was quantified by the parameters like, maximum width of the furrow, depth of furrow, width of the furrow, height of the ridges and ridge to ridge distance as shown in figure 1 (Manuwa, 2009).

\section{Tool width to furrow width ratio}

The dimensions of different selected tools and average width of furrow formed during different treatments were measured and tool furrow width ratios were calculated using following formula: 


$$
R_{T F}=\frac{\text { Width of tool }(m)}{\text { Average width of furrow }(m)}
$$

\section{Results and Discussion}

The effect of tool shape, operating speed and working depth of selected tillage tools on draft, specific draft, soil disturbance and tool width to furrow width ratio was studied in the soil bin and the results were shown as follows:

\section{Effect of tool shape, forward speed and depth of operation on draft and specific draft}

The measured draft and specific draft forces were obtained for tillage tools, depth and forward speed were tabulated (Table 2). The results showed that Draft forces increased significantly for all tools when operating depth was increased from $5-15 \mathrm{~cm}$. Increase in the draft is due to greater depth of penetration, larger surface area and more soil resistance which requires more force to break up the soil. The reason for increased draft force for all tools with increase of tillage depth and forward speed level is the high acceleration to the soil particles during their displacement. According to Manuwa, (Manuwa, 2009), the reason being that at higher depths more soil volume is considered, soil becomes stiffer and denser (due to overburden pressure) and so strength properties vary. The reason for maximum value of draft for Sweep-2 was due to larger area of contact, larger cutting edge of the tool and due to soil abrasion Gupta et al., 2004).

It was observed that, at $5 \mathrm{~km} / \mathrm{h}$ forward speed and $15 \mathrm{~cm}$ operating depth the Sweep-2 gives the maximum value of draft $(1,208.33 \mathrm{~N})$. Similarly, at $5 \mathrm{~cm}$ operating depth and $3 \mathrm{~km} / \mathrm{h}$ forward speed, Shovel-1 gives the minimum value of draft $(193.67 \mathrm{~N})$. By comparing all the three tools, Sweep-2 requires maximum draft force than Sweep-1 than Shovel-1 (i.e. $\mathrm{T}-2>\mathrm{T}-1>\mathrm{T}-3)$.

The statistical analysis of draft shown that, the applied model is significant at 1 percent level of significance (Table 3). The independent parameters such as, tools shape, depth of operation and forward speed had influenced the draft at 1 percent level of significance. Also, the interaction of all the parameters were also affected the draft values significantly. The standard deviation was 15.11 and co-efficient of variation is $2.30 \%$ which is below the acceptable limit.

There were large differences was observed in specific draft between the different shovel and sweeps. The measured working depth and specific draft for were presented in tables 2 . Specific draft observed was lowest for the Shovel-1 (T-3) and maximum for Sweep-1. It is also observed that the specific draft for Sweep-1, goes on increases up to certain level as operating depth increase, after that point it goes on decrease as depth increases. The reason for decrease in specific draft of Sweep1 was, as depth of penetration increases the soil disturbance becomes less and the furrow formed becomes narrow, due to this area of the furrow formed goes on decreases and draft requirement increases (Goodwin, 2007). Also in the range of depth considered, the increase in specific draught became higher as the tine, width increased.

This is because the amount of soil displaced by narrow tines is considerably lower than that disturbed by wide tines. Inertial forces are more significant for wide tines than narrow tines (Manuwa, 2009). Similarly the specific draft for Sweep-2 and Shovel-1 goes on increases as operating depth increases.

The statistical analysis of specific draft shown that, the applied model is significant at 1 
percent level of significance (Table 4). The independent parameters, tools shape and depth of operation had influenced the specific draft at 1 percent level of significance whereas forward speed had influence at 5\% level of significance.

Also, the interaction of tool and depth were also affected the specific draft values significantly at $1 \%$ level of significance (Table 3). The standard deviation was 1.25 and co-efficient of variation is $28.21 \%$.
Effect of tool shape, forward speed and depth of operation on soil disturbance parameters

For the purpose of analysis, the general form of soil disturbance was quantized by the parameters shown in Fig. 1. The parameters used to describe soil disturbance include: maximum width of soil throw (TDW); maximum width of soil cut (WFs) also referred to as width of crescent; the ridge-toridge distance (RRD); the height of the ridge (hr); after plough furrow depth (df) and the tool width (w) and were recorded (Table 5).

Table.1 Detailed plan of work for conducting the experiments

\begin{tabular}{|c|c|c|}
\hline $\begin{array}{l}\text { Independent } \\
\text { parameters }\end{array}$ & Levels & Dependent parameters \\
\hline Tools & $\begin{array}{l}\mathrm{T}_{1} \text { (Sweep-1) } \\
\mathrm{T}_{2} \text { (Sweep-2) }\end{array}$ & \multirow{3}{*}{$\begin{array}{l}\text { 1. Draft } \\
\text { 2. Specific draft } \\
\text { 3. Soil disturbance } \\
\text { parameters } \\
\text { 4. Tool width to furrow } \\
\text { width ratio }\end{array}$} \\
\hline Operating speed & $\begin{array}{c}\mathrm{T}_{3} \text { (Shovel-1) } \\
\mathrm{S}_{1}(3 \mathrm{~km} / \mathrm{h}) \\
\mathrm{S}_{2}(4 \mathrm{~km} / \mathrm{h}) \\
\mathrm{S}_{3}(5 \mathrm{~km} / \mathrm{h})\end{array}$ & \\
\hline Operating depth & $\begin{array}{l}\mathrm{D}_{1}(05 \mathrm{~cm}) \\
\mathrm{D}_{2}(10 \mathrm{~cm}) \\
\mathrm{D}_{3}(15 \mathrm{~cm})\end{array}$ & \\
\hline
\end{tabular}

Table.2 Pattern of draft and specific draft for different tool shape, Forward speed and operating depth

\begin{tabular}{|c|l|c|c|c|c|c|c|}
\hline \multirow{2}{*}{ Tool } & \multirow{2}{*}{ Depth } & \multicolumn{3}{|c|}{ Draft $(\mathbf{N})$} & \multicolumn{3}{|c|}{ Specific Draft $\left(\mathbf{N} / \mathbf{c m}^{2}\right)$} \\
\cline { 3 - 8 } & & Speed-1 & Speed-2 & Speed-3 & Speed-1 & Speed-2 & Speed-3 \\
\hline \multirow{3}{*}{ Tool-1 } & D1 $(5 \mathrm{~cm})$ & 425.00 & 629.67 & 681.67 & 9.94 & 15.17 & 9.47 \\
\cline { 2 - 8 } & D2 $(10 \mathrm{~cm})$ & 631.00 & 786.67 & 834.33 & 3.37 & 4.22 & 4.85 \\
\cline { 2 - 8 } & D3 $(15 \mathrm{~cm})$ & 732.67 & 864.00 & 962.00 & 2.87 & 3.13 & 3.41 \\
\hline \multirow{3}{*}{ Tool-2 } & D1 $(5 \mathrm{~cm})$ & 521.33 & 700.33 & 814.00 & 3.69 & 4.41 & 4.78 \\
\cline { 2 - 8 } & D2 $(10 \mathrm{~cm})$ & 743.00 & 871.00 & $1,004.33$ & 3.52 & 4.29 & 5.21 \\
\cline { 2 - 8 } & D3 $(15 \mathrm{~cm})$ & 854.67 & $1,023.33$ & $1,208.33$ & 3.76 & 4.01 & 5.92 \\
\hline \multirow{3}{*}{ Tool-3 } & D1 $(5 \mathrm{~cm})$ & 193.67 & 265.67 & 373.33 & 2.45 & 1.88 & 2.83 \\
\cline { 2 - 8 } & D2 $(10 \mathrm{~cm})$ & 273.33 & 384.67 & 481.00 & 1.51 & 1.80 & 2.77 \\
\cline { 2 - 8 } & D3 $(15 \mathrm{~cm})$ & 385.00 & 505.33 & 617.33 & 1.74 & 2.56 & 2.72 \\
\hline
\end{tabular}


Table.3 Analysis of variance (ANOVA) for draft

\begin{tabular}{llllll}
\hline Source & $\begin{array}{l}\text { Sum of } \\
\text { squares }\end{array}$ & Df & Mean square & F-value & $\begin{array}{l}\text { p-value } \\
\text { Prob }>\mathrm{F}\end{array}$ \\
\hline Model & $5.223 \mathrm{E}+006$ & 26 & $2.009 \mathrm{E}+005$ & $879.30^{*}$ & $<0.0001$ \\
A-Tool & $3.221 \mathrm{E}+006$ & 2 & $1.611 \mathrm{E}+006$ & $7050.28^{*}$ & $<0.0001$ \\
B-Depth & $1.086 \mathrm{E}+006$ & 2 & $5.429 \mathrm{E}+005$ & $2376.61^{*}$ & $<0.0001$ \\
C-Speed & $8.248 \mathrm{E}+005$ & 2 & $4.124 \mathrm{E}+005$ & $1805.29^{*}$ & $<0.0001$ \\
AB & 42153.09 & 4 & 10538.27 & $46.13^{*}$ & $<0.0001$ \\
AC & 31446.86 & 4 & 7861.72 & $34.41^{*}$ & $<0.0001$ \\
BC & 7260.94 & 4 & 1815.23 & $7.95^{*}$ & $<0.0001$ \\
ABC & 9927.14 & 8 & 1240.89 & $5.43^{*}$ & $<0.0001$ \\
Pure Error & 12336.00 & 54 & 228.44 & & \\
Cor Total & $5.235 \mathrm{E}+006$ & 80 & & & \\
\hline
\end{tabular}

*significant at $1 \%$ level of significance

$* *$ significant at $5 \%$ level of significance

Table.4 Analysis of variance (ANOVA) for specific draft

\begin{tabular}{llllll}
\hline Source & $\begin{array}{l}\text { Sum of } \\
\text { squares }\end{array}$ & Df & Mean square & F-value & $\begin{array}{l}\text { p-value } \\
\text { Prob }>\text { F }\end{array}$ \\
\hline Model & 763.42 & 26 & 29.36 & $18.69^{*}$ & $<0.0001$ \\
A-Tool & 234.29 & 2 & 117.15 & $74.55^{*}$ & $<0.0001$ \\
B-Depth & 132.03 & 2 & 66.02 & $42.01^{*}$ & $<0.0001$ \\
C-Speed & 18.60 & 2 & 9.30 & $5.92^{* *}$ & 0.0047 \\
AB & 284.87 & 4 & 71.22 & $45.2^{*}$ & $<0.0001$ \\
AC & 29.00 & 4 & 7.25 & 4.61 & 0.0028 \\
BC & 23.63 & 4 & 5.91 & 3.76 & 0.0090 \\
ABC & 41.00 & 8 & 5.12 & 3.26 & 0.0042 \\
Pure Error & 84.85 & 54 & 1.5 & & \\
Cor Total & 848.28 & 80 & & & \\
\hline
\end{tabular}


Table.5 Pattern showing soil disturbance data for sweep-1, sweep-2 and shovel-1

\begin{tabular}{|c|c|c|c|c|c|c|c|}
\hline Tool & Depth & Speed & RRD & Wfs & TDW & $\mathrm{Hr}$ & Df \\
\hline \multirow{9}{*}{ T-1 } & \multirow{3}{*}{ D-1 } & S-1 & 20.33 & 5.33 & 30.00 & 1.83 & 3.33 \\
\hline & & S-2 & 22.00 & 5.67 & 31.33 & 1.67 & 3.00 \\
\hline & & S-3 & 21.33 & 5.67 & 32.00 & 2.17 & 5.33 \\
\hline & \multirow{3}{*}{ D-2 } & S-1 & 31.33 & 11.83 & 42.67 & 4.67 & 8.67 \\
\hline & & S-2 & 31.33 & 11.67 & 42.67 & 5.33 & 8.67 \\
\hline & & S-3 & 28.67 & 11.00 & 39.33 & 3.33 & 8.67 \\
\hline & \multirow{3}{*}{ D-3 } & S-1 & 36.67 & 12.67 & 48.67 & 5.67 & 10.33 \\
\hline & & S-2 & 33.33 & 14.00 & 47.00 & 4.00 & 11.67 \\
\hline & & S-3 & 34.67 & 13.67 & 46.67 & 4.00 & 11.67 \\
\hline \multirow{9}{*}{ T-2 } & \multirow{3}{*}{ D-1 } & S-1 & 29.67 & 5.67 & 40.33 & 3.33 & 8.00 \\
\hline & & S-2 & 33.00 & 6.67 & 46.00 & 3.67 & 8.00 \\
\hline & & S-3 & 33.33 & 6.00 & 48.00 & 3.00 & 8.67 \\
\hline & \multirow{3}{*}{ D-2 } & S-1 & 36.00 & 7.67 & 47.33 & 5.00 & 9.67 \\
\hline & & S-2 & 34.67 & 7.33 & 49.67 & 5.00 & 9.67 \\
\hline & & S-3 & 34.67 & 6.67 & 50.67 & 5.33 & 9.33 \\
\hline & \multirow{3}{*}{ D-3 } & S-1 & 39.67 & 9.00 & 58.00 & 5.67 & 9.33 \\
\hline & & S-2 & 40.00 & 9.33 & 56.67 & 5.67 & 10.33 \\
\hline & & S-3 & 40.67 & 8.33 & 58.00 & 4.67 & 8.33 \\
\hline \multirow{9}{*}{ T-3 } & \multirow{3}{*}{ D-1 } & S-1 & 18.67 & 6.33 & 29.33 & 2.67 & 6.33 \\
\hline & & S-2 & 23.00 & 7.33 & 32.67 & 4.67 & 9.33 \\
\hline & & S-3 & 22.00 & 6.00 & 35.00 & 4.67 & 9.67 \\
\hline & \multirow{3}{*}{ D-2 } & S-1 & 28.33 & 7.00 & 37.00 & 5.67 & 10.67 \\
\hline & & S-2 & 29.00 & 5.67 & 42.00 & 5.00 & 12.33 \\
\hline & & S-3 & 25.33 & 7.00 & 38.67 & 4.67 & 9.33 \\
\hline & \multirow{3}{*}{ D-3 } & S-1 & 32.67 & 8.33 & 49.33 & 4.67 & 10.00 \\
\hline & & S-2 & 31.33 & 9.67 & 51.00 & 5.33 & 9.33 \\
\hline & & S-3 & 32.67 & 9.67 & 52.33 & 4.00 & 10.00 \\
\hline
\end{tabular}

Table.6 Analysis of variance (ANOVA) for RRD

\begin{tabular}{llllll}
\hline Source & $\begin{array}{l}\text { Sum of } \\
\text { squares }\end{array}$ & Df & Mean square & F-value & $\begin{array}{l}\text { p-value } \\
\text { Prob }>\text { F }\end{array}$ \\
\hline Model & 2990.91 & 26 & 115.04 & $29.12^{*}$ & $<0.0001$ \\
A-Tool & 1155.88 & 2 & 577.94 & $146.29^{*}$ & $<0.0001$ \\
B-Depth & 1619.14 & 2 & 809.57 & $204.92^{*}$ & $<0.0001$ \\
C-Speed & 5.36 & 2 & 2.68 & 0.68 & 0.5118 \\
AB & 96.79 & 4 & 24.20 & $6.13^{*}$ & 0.0004 \\
AC & 12.57 & 4 & 3.14 & 0.80 & 0.5334 \\
BC & 81.31 & 4 & 20.33 & $5.15^{* *}$ & 0.0014 \\
ABC & 19.88 & 8 & 2.48 & 0.63 & 0.7499 \\
Pure Error & 213.33 & 54 & 3.95 & & \\
Cor Total & 3204.25 & 80 & & & \\
\hline
\end{tabular}


Table.7 Analysis of variance (ANOVA) for TDW

\begin{tabular}{llllll}
\hline Source & $\begin{array}{l}\text { Sum of } \\
\text { squares }\end{array}$ & Df & Mean square & F-value & $\begin{array}{l}\text { p-value } \\
\text { Prob }>\mathrm{F}\end{array}$ \\
\hline Model & 56860.2 & 26 & 218.69 & $26.24^{*}$ & $<0.0001$ \\
A-Tool & 1879.80 & 2 & 939.90 & $112.78^{*}$ & $<0.0001$ \\
B-Depth & 3421.80 & 2 & 1710.90 & $205.31^{*}$ & $<0.0001$ \\
C-Speed & 79.28 & 2 & 39.64 & 4.76 & 0.0125 \\
AB & 137.53 & 4 & 34.38 & $4.13^{* *}$ & 0.0055 \\
AC & 55.60 & 4 & 13.90 & 1.67 & 0.1708 \\
BC & 87.16 & 4 & 21.79 & $2.61^{* * *}$ & 0.0452 \\
ABC & 24.84 & 8 & 3.10 & 0.37 & 0.9306 \\
Pure Error & 450.00 & 54 & 8.33 & & \\
Cor Total & 6136.02 & 80 & &
\end{tabular}

Table.8 Analysis of variance (ANOVA) for Wfs

\begin{tabular}{llllll}
\hline Source & $\begin{array}{l}\text { Sum of } \\
\text { squares }\end{array}$ & Df & Mean square & F-value & $\begin{array}{l}\text { p-value } \\
\text { Prob }>\mathrm{F}\end{array}$ \\
\hline Model & 529.41 & 26 & 20.36 & $24.90^{*}$ & $<0.0001$ \\
A-Tool & 131.60 & 2 & 65080 & $80.45^{*}$ & $<0.0001$ \\
B-Depth & 266.82 & 2 & 133.41 & $163.11^{*}$ & $<0.0001$ \\
C-Speed & 2.90 & 2 & 1.45 & 1.77 & 0.1801 \\
AB & 112.49 & 4 & 28.12 & $34.38^{*}$ & $<0.0001$ \\
AC & 2.20 & 4 & 0.55 & 0.67 & 0.6145 \\
BC & 6.31 & 4 & 1.58 & 1.93 & 0.1189 \\
ABC & 7.10 & 8 & 0.89 & 1.08 & 0.3877 \\
Pure Error & 44.17 & 54 & 0.82 & & \\
Cor Total & 573.58 & 80 & & & \\
*significant at 1\% level of significance & $* *$ significant at 5\% level of significance &
\end{tabular}

Table.9 Pattern of tool width to furrow width ratio for sweep-1, sweep-2 and shovel-1

\begin{tabular}{ccccc}
\hline Tool & Depth & Speed-1 & Speed-2 & Speed-3 \\
\hline \multirow{4}{*}{ Tool 1 } & D1 $(05 \mathrm{~cm})$ & 3.56 & 3.35 & 3.35 \\
& D2 $(10 \mathrm{~cm})$ & 1.61 & 1.63 & 1.73 \\
\cline { 2 - 5 } Tool 2 & D3 $(15 \mathrm{~cm})$ & 1.50 & 1.36 & 1.39 \\
\cline { 2 - 5 } & D1 $(05 \mathrm{~cm})$ & 4.59 & 3.90 & 4.33 \\
\cline { 2 - 5 } Tool 3 & D2 $(10 \mathrm{~cm})$ & 3.39 & 3.55 & 3.90 \\
& D3 $(15 \mathrm{~cm})$ & 2.89 & 2.79 & 3.12 \\
\hline & D1 $(05 \mathrm{~cm})$ & 1.11 & 0.95 & 1.31 \\
& D2 $(10 \mathrm{~cm})$ & 1.24 & 1.24 & 0.59 \\
& D3 $(15 \mathrm{~cm})$ & 0.60 & 0.64 & 0.55 \\
\hline
\end{tabular}


Plate.1 Selected tillage tools for the experiment. (a) Sweep-1, (b) Sweep-2 (c) Shovel-1

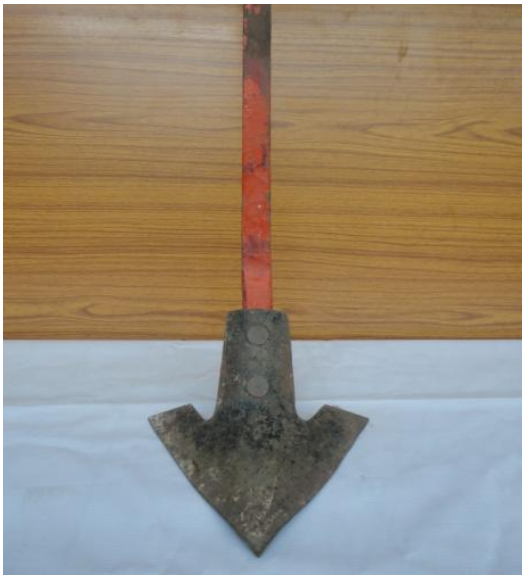

(a)

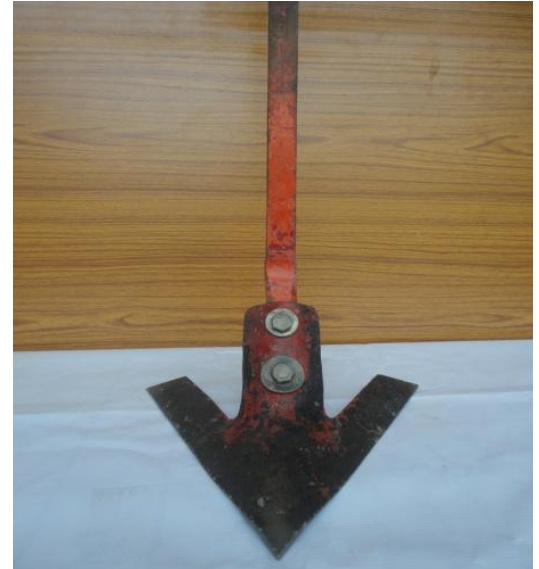

(b)

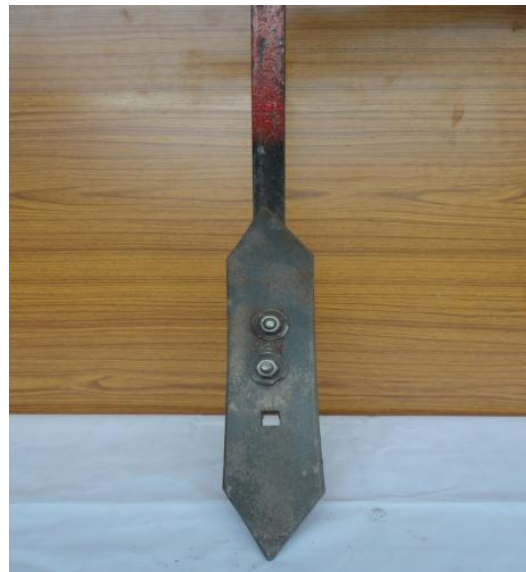

(c)

Fig.1 Parameters used to define soil disturbance by tillage tool: maximum width of soil throw (TDW); maximum width of soil cut (Wfs); ridge-to-ridge distance (RRD); height of ridge (hr); after plough depth (df); tool width (w), (Manuwa,2009)

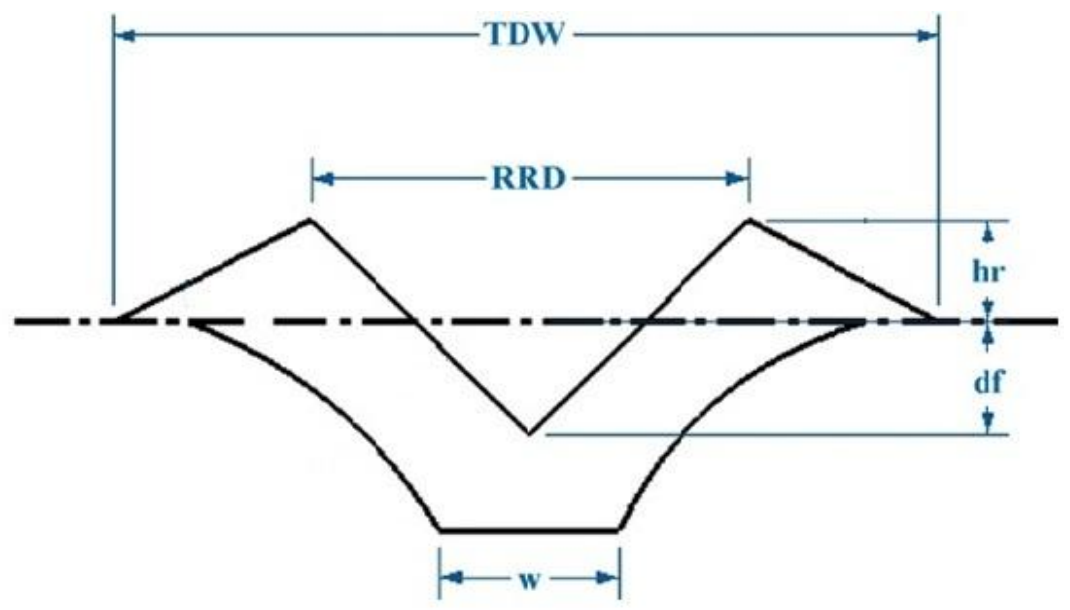

To compare the three tools, we consider only three parameters (i.e. maximum width of soil throw, ridge to ridge height and furrow bottom width). From this experiment we observed that soil disturbance is mainly dependent on forward speed and depth of operation. So we compare the soil disturbance parameters in terms of speed and depth with respective to all the tools.

The effect of depth of operation of the tines on soil disturbance was observed for a forward speed ( 3 , 4 and $5 \mathrm{~km} / \mathrm{h})$, depth $(5,10$ and $15 \mathrm{~cm}$ ) for three tools with the results presented in Table 3. As the tool moved through the soil in the soil bin, the soil was disturbed as it was cut and thrown to the sides of the tool. The soil disturbance generated was observed, assessed and analyzed. The width of the tool strongly influenced the soil disturbance parameters as they all increased as the working depth increased but less proportionately. This was also similar to the findings reported by Manuwa (Manuwa, 
2009). This is because the major factors that control the nature of soil failure or disturbance are the aspect ratio (depth/width ratio) and the rake angle. As the depth/width ratio increased, the nature of soil failure changed. The inertial forces influenced the distance that the soil was thrown away from the tool path. For all the three levels of speed, the furrow level was filled to an upper level mostly with pulverized soil that fell back, this influenced the after furrow depth.

The statistical analysis of RRD shown that, the applied model is significant at 1 percent level of significance (Table 6). The independent parameters, tool shape and depth of operation had influenced the RRD at 1 percent level of significance and speed has no effect on RRD. Also, the interaction of tooldepth and depth-speed interactions were affected the RRD values significantly at $1 \%$ and 5\% level of significance respectively. The standard deviation was 1.99 and co-efficient of variation is $6.52 \%$.

Similarly the statistical analysis of TDW shown that, the applied model is significant at 1 percent level of significance (Table 7). The independent parameters, tools shape, speed and depth of operation had influenced the TDW at 1 percent level of significance. Also, the interaction of tool-depth and depth-speed interactions were affected the TDW values significantly at 5\% level of significance. The standard deviation was 2.89 and co-efficient of variation is 6.60 percent.

The statistical analysis of Wfs shown that, the applied model is significant at 1 percent level of significance (Table 8). The independent parameters, tools shape and depth of operation had influenced the Wfs at 1 percent level of significance. Also, the interaction of tool-depth was affected the Wfs values significantly at $1 \%$ level of significance. The standard deviation was 0.90 and co-efficient of variation is $10.86 \%$.
Effect of tool shape, forward speed and depth of operation on tool width to furrow width ratio

The ratio of tool width to the furrow width ratio gives an idea about the workability of the tool (Table 9). To achieve maximum field capacity and required tilth of the soil, this ratio may be used for analysis and the value of this ratio should as minimum as possible for proper operation. It was observed that, the tool to the furrow width ratio was dependent on geometry of tillage tools and depth of operation and it is independent of forward speed. In this experiment the minimum value of the ratio was observed for Sweep-1 (1.36) at speed-2 and depth-3, whereas, maximum value was observed (3.56) at depth-1 and speed-1.

Based on all the values of dependent parameters (tools, speeds and depths) and dependent parameters (draft, specific draft, soil disturbance parameters and tool width to furrow width ratio) with three replications were analyzed in ANOVA software and result of this analysis show that Sweep-1 shows the results significantly with minimum value of draft and maximum value of soil disturbance among the all three tools. After optimization of operational parameters, sweep 1 with speed of operation of $3 \mathrm{~km} / \mathrm{h}$ and shovel 2 with speed of operation of $4 \mathrm{~km} / \mathrm{h}$ was recommended at $15 \mathrm{~cm}$ depth of operation with a desirability level of 0.653 .

\section{References}

Ademosun, O.C. 1990. The design and operation of a soil tillage dynamics equipment. Niger. Eng., 25(1): 51-57.

Al-Janobi, A. and Eldin, A.M. 1997. Development of a soil bin test facility for soil tillage tool interaction studies. Research Bulletin, Agricultural 
Research Center, King Saud University. 72: 5 - 26 .

Davidson, J.B., and Chase, L.W. 1908. Farm Machinery and Farm Motors. Orange Judd Company, New York.

Goodwin, R.J. 2007. A review of the effect of implement geometry on soil failure and implement forces. Soil Tillage Res., 97: 331-340.

Grisso, R.D., Yasin, M. and Kocher, M.F. 1994. Tillage Implement Forces Operating in Silty Clay Loam. ASAE paper No.94-1532, St. Joseph, Mich., USA.

Gupta, A.K., Jesudas, D.M., Das, P.K. and Basu, K. 2004. Performance evaluation of different types of steel for duck foot sweep application. Biosys. Eng., 88(1): 63-74.

Makanga, J.T., Salokhe, V.M. and GeeClough, D. 1997. Effects of tine rake angle and aspect ratio on soil reactions in dry loam soil. J. Terramech., 34: 250-235.

Manuwa, S.I. 2009. Performance evaluation of tillage tines operating under different depths in a sandy soil. Soil Tillage Res., 103: 399-405.

Marakoglu, T., and Carman, K. 2009. Effects of design parameters of cultivator share on draft force and soil loosening in soil bin. J. Agron., 8(1): 21-26.

Mardani, A.A., Shahidi, K., Rahmani, A., Mashoofi, B. and Karimmaslak. H., 2010. Studies on a long soil bin for soiltool interaction. Cercetări Agronomice Moldova, 43(2): 5-10.

Spoor, G. and Godwin, R.J. 1978. Experimental Investigation into the deep loosening of soil by rigid tines. $J$. Agri. Engi. Res., 23(3): 243-258.

\section{How to cite this article:}

Shrinivas Deshpande and Sunil Shirwal. 2017. Effect of Operational Parameters of Selected Tillage Tools in Soil Bin. Int.J.Curr.Microbiol.App.Sci. 6(6): 1051-1061. doi: https://doi.org/10.20546/ijcmas.2017.606.121 